\title{
Oficinas de atividades com jovens da escola pública: tecnologias sociais entre educação e terapia ocupacional *
}

Roseli Esquerdo Lopes ${ }^{1}$ Patrícia Leme de Oliveira Borba ${ }^{2}$ Natalia Keller de Almeida Trajber ${ }^{3}$ Carla Regina Silva ${ }^{4}$ Brena Talita Cuel ${ }^{5}$

\begin{abstract}
Acredito
Acredito ser o mais valente, nessa luta do rochedo com o mar

E com o ar!

É hoje o dia da alegria

E a tristeza, nem pode pensar em chegar

Diga espelho meu...

Didi e Mestrinho (1982)
\end{abstract}

\section{Introdução}

Este trabalho discute a proposição de Oficinas de Atividades com jovens no interior da escola pública. São elaborações que partem de atividades de extensão universitária que vêm sendo realizadas pelo Núcleo UFSCar (Universidade Federal de São Carlos) do Projeto METUIA ${ }^{6}$ em uma escola pública da periferia da cidade de São Carlos (SP), e, também, de pesquisas desenvolvidas por esse mesmo grupo, as quais se debruçaram sobre a temática da Educação de Tempo Integral.

\begin{abstract}
Compreendemos a Extensão como uma prática acadêmica que integra as atividades de Ensino e Pesquisa articulada às demandas sociais [...], o que propicia não só o diálogo entre a Universidade e a Sociedade, mas possibilita, também, a democratização do saber acadêmico e a busca de respostas às demandas suscitadas pelo desejo permanente de aperfeiçoamento sociocultural e profissional gerado pelos próprios cursos de graduação e pós-graduação, e, mais amplamente, pela Sociedade. (Lopes et al., 2008a, p.119-20)
\end{abstract}

O METUIA/UFSCar, desde 2001, tem acumulado experiências no campo da infância e, sobretudo, da juventude brasileira. Temos focalizado a juventude pobre ${ }^{7}$ urbana, buscando atender à necessidade contemporânea de desenvolvimento e ampliação de alternativas de prevenção às situações de vulnerabilidade e violência, por meio da educação e da defesa da cidadania, bem como assumindo o desafio de criação de metodologias participativas. Trata-se de uma temática complexa e para a qual há um pequeno acúmulo de produção de

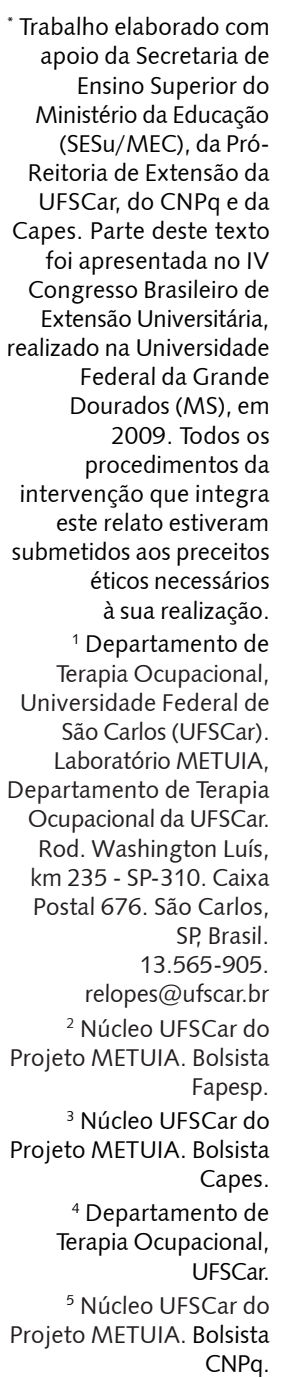


OFICINAS DE ATIVIDADES COM JOVENS ...

material sobre as possibilidades de intervenção direcionadas para a produção de tecnologias sociais que se dediquem à criação de espaços de participação democrática e ampliem a rede de sociabilidades e oportunidades daqueles jovens, na direção de envolvê-los concretamente numa atenção personalizada que tenha como parâmetro a possibilidade de construção de perspectivas de futuro a partir da autonomia do sujeito envolvido (Lopes et al., 2008b).

Sabe-se que a escola pública brasileira tem passado por um intenso processo de transformação e, apesar de o país ter instituído legalmente sua universalização no Ensino Fundamental, o que tem garantido o ingresso de crianças, jovens e adultos, ainda apresenta inúmeras dificuldades frente aos processos de permanência, progressão e conclusão na idade adequada. O direito à educação democrática, que se define pela equidade e qualidade para todos ${ }^{8}$, permanece como meta (Lopes, Silva, Malfitano, 2006).

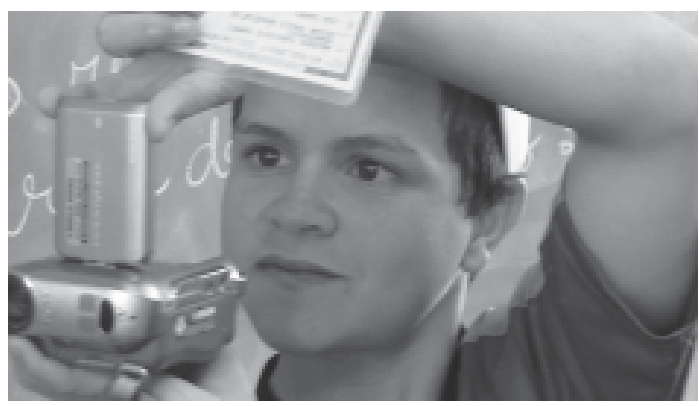

Figura 1. Elaboração de vídeos e documentários

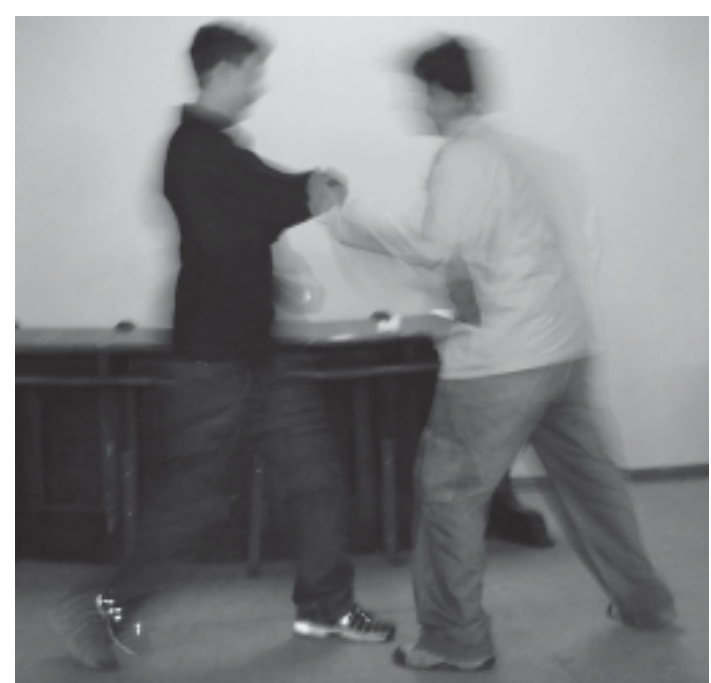

Figura 2. Construções e apresentações de esquetes
${ }^{6} \mathrm{O}$ Projeto METUIA se constituiu, desde 1998, como um grupo interinstitucional com ações no âmbito do ensino, da pesquisa e da extensão, em defesa da cidadania das populações em processos de ruptura das redes sociais de suporte. Dentre as atividades que vem realizando, temos os programas de

intervenção de terapia ocupacional, em suas interconexões com os setores da assistência social, da cultura, da educação e, também, com a saúde.

Atualmente, dois núcleos estão em atividade: o da USP e o da UFSCar

(Barros, Lopes, Galheigo, 2007).

7 "a designação utilizada - jovens pobres - é intencional, uma vez que não se pretende aceitar alguns adjetivos que vêm sendo adotados, como 'excluídos, vulneráveis, em situação de risco ou miseráveis'". (Sposito, Corrochano, 2005, p.146)

${ }^{8}$ Para Gramsci, não há em termos educacionais, qualidade sem

quantidade (escola para todos), mas esta última, por si só, não representa a primeira (Mancacorda, 1989).

\section{O campo da escola pública}

Ferreira Jr. e Bittar (2006) apontam três grandes problemas na conjunção educacional da atualidade, quais sejam: o acesso, a permanência e a aprendizagem efetiva, dentre os quais o professor tem influência direta nos dois últimos se tiver uma formação adequada e uma remuneração condizente. Porém, a questão do acesso tem sido a única atacada concretamente pelos sucessivos governos, o que é pouco para transformar nossa realidade educacional. 
${ }^{9}$ Compreendido como o conjunto de bens, saberes, crenças, práticas, comportamentos e habitus da humanidade, a partir das reflexões de Paulo Freire sobre patrimônio cultural (1979) e de Bourdieu (2008) acerca do capital cultural.

Para Gimeno Sacristán e Pérez Gómez (1998), somente a escola pode cumprir a função de reelaboração crítica e reflexiva da cultura dominante, devendo disso se ocupar, considerando o fato de que, na contemporaneidade, perdeu o papel hegemônico na transmissão e distribuição da informação.

No Brasil, na década de 1990, o prolongamento da escolaridade tornou-se impositivo, sobretudo em relação ao mercado de trabalho, que passou a exigir uma escolaridade maior e mais sofisticada. Nesse contexto, a Lei de Diretrizes e Bases da Educação de 1996 reformulou o Ensino Médio com o objetivo de expandi-lo e melhorar sua qualidade (Marcílio, 2005).

Apesar de ser um setor fundamental nas políticas públicas para a juventude, 0 Ensino Médio enfrenta cotidianamente o embate entre seus objetivos e suas reais condições de projetar a imensa maioria de adolescentes e jovens brasileiros em direção a uma vida de realizações, seja no mercado de trabalho, seja na formação para o Ensino Superior. Um percentual absolutamente relevante de jovens é excluído da escola no Brasil, num processo em que vivenciam a violência dessa discriminação produzida no contexto escolar, com a não-manutenção do acesso, com a falta de qualidade de ensino e, por fim, com a enorme barreira da desigualdade na construção de seus projetos de vida (Lopes, Silva, 2007).

Conforme Silva (2007b), percorremos, na escola, um caminho de formação do "eu", iniciamos uma busca pelo significado da vida; no entanto, somos submetidos a uma razão de controle exercida pelas instituições, que nos localizam, nos observam, nos expõem e buscam determinar aquilo que achamos que desejamos. Considerando que o papel da escola seja o de emancipar os indivíduos, instala-se um paradoxo: se, por um lado, deve-se possibilitar aos alunos compreenderem os processos de submissão e dominação aos quais estão expostos (para propiciar emancipação e autonomia), levando-os a resistir, a procurar por transformações; por outro lado, ela de fato mantém e legitima as desigualdades sociais (Bourdieu, 2008).

Caberia à escola "o desafio de ser um grande palco de projetos coletivos" (Debortoli, 2002, p.44), buscando transformar-se para realizar sua função na produção e difusão do patrimônio cultural ${ }^{9}$ e na formação de sujeitos autônomos, deixando de produzir diferenças instituintes e lidando com a diversidade que the é inerente. Uma escola que não se conforme em ser uma máquina de hierarquizar pode oferecer a oportunidade de rompimento com a lógica da dominação, passando a ser um lugar de expressão, de subversão e de criação.

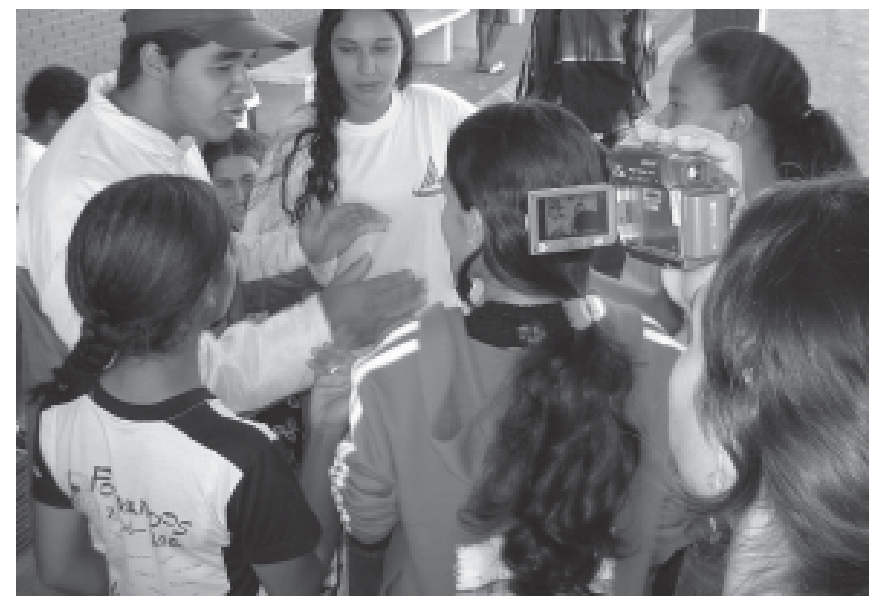

Figura 3. Elaboração de vídeos e documentários 
A pedagogia, como prática cultural e intencional, deve lançar mão de todo seu potencial para transformar e efetivar a formação dos cidadãos nas mais diferentes instâncias da vida contemporânea escola, trabalho, família, grupos sociais, etc. - valendo-se, para isso, de dois fatores inerentes à prática pedagógica: a intencionalidade e a diferença. A escola, em particular, como local destinado a essa prática, deve ser um espaço de encontro e valorização das diferenças como multiplicidade referencial.

Ao abraçar a diferença, a escola pode repensar e desconstruir flagelos clássicos de sua história, como a evasão, a repetência, a violência, vistos tradicionalmente como "fracasso escolar", ou melhor, como "fracassos individuais", quando, na verdade, são fracassos sociais, intencionais e educacionais (ou pedagógicos).

A questão do exercício do poder na escola precisaria ser assumida e explicitada para que houvesse a possibilidade de transformá-la; contudo, temos a clareza da dimensão dessa tarefa e de suas dificuldades, diretamente ligadas ao que Bourdieu (1998) denomina ritos de instituição. Estes se referem a todo e qualquer rito que exerce um efeito de consagração, que notifica a alguém sua identidade (Bourdieu, 1998). Para entrar na escola e nela permanecer, todos são submetidos a ritos que os instituem como pertencentes ou não ao sistema escolar e a uma escola específica. Tais ritos são: provas objetivas, cadastros com uma infinidade de dados e documentos, filas, esperas, disputas (mesmo aquelas supostamente despersonificadas, como a satisfação de requisitos socioeconômicos, por exemplo), relações e comportamentos. É importante ressaltar que o rito tem caráter arbitrário e este, muitas vezes, está dissimulado, oculto, sob uma naturalização de certas "diferenças" artificialmente promovidas. Porém, segundo Bourdieu: "prega-se apenas aos convertidos", ou seja, apenas se instituem aqueles que, de certa maneira, já interiorizaram essas diferenças como reais, naturais e legítimas (Bourdieu, Saint-Martin, 2008, p.200).

Nossa escola, em vez de contribuir para a emancipação dos sujeitos, institui quem chegará até o final e quem não o logrará. Uma das funções da instituição seria desencorajar duradouramente a possibilidade da passagem, da transgressão, da deserção, da demissão. Em nossas escolas - aqui com foco naquelas frequentadas pela maioria dos jovens brasileiros, ou seja, na escola pública -, é assustadora a violência (física ou simbólica) a que estão submetidos os alunos; nelas, a evasão escolar se dá como uma deserção, um ato demissional, a partir da constatação clara de que aquele espaço pouco Ihes diz respeito. Vale pensar também na constatação de que os ritos de instituição aos quais os alunos se sujeitam não têm sequer cumprido seu papel de promover o "sentir-se parte", uma vez que há sempre ritos mais intransponíveis, para não dizer excludentes, num processo de dentro para fora, isto é, expulsando quem havia sido "aceito".

Para lidar com essa questão, Carvalho e Pinto (2002) resgatam a pedagogia da autonomia proposta por Freire (1999), partindo de experiências estimuladoras da decisão e da responsabilidade, tendo, como parâmetros, o respeito e a liberdade. A disposição para a ação, participação, autonomia e democracia é uma força propulsora do desenvolvimento, e não um obstáculo a ser vencido.

Construir a democracia no ambiente escolar não é uma tarefa fácil. Para Sorrentino (2002), a participação de fato poderia ser garantida com a efetivação: da disponibilidade de informações, dos espaços de locução, da infraestrutura básica, da coletivização das decisões e do comprometimento (ou "pertencimento") de cada sujeito em relação ao processo.

As experiências extensionistas desenvolvidas pelo METUIA/UFSCar, nessa perspectiva, têm lidado com essas problemáticas e contribuído com propostas de intervenção que buscam solucioná-las.

Este relato é uma síntese do trabalho que o grupo tem desenvolvido no interior da escola pública desde 2005. Assim, o que aqui reunimos em "Oficinas de Atividades" é fruto de diferentes processos e formatos de proposições que procuraram responder a demandas da própria escola e dos jovens.

Inicialmente, as oficinas ocorreram em cinco escolas estaduais de Ensino Médio de diferentes regiões da cidade de São Carlos (SP), tendo como eixos o levantamento e a reflexão acerca da violência na e da escola. Aconteciam semanalmente, agregadas transversalmente ao currículo de três turmas de cada escola, durante o primeiro semestre de 2006, no período diurno e noturno; trabalhou-se com cerca de quatrocentos e cinquenta alunos. A equipe era composta por terapeutas ocupacionais e estudantes de graduação da UFSCar. 
Em agosto de 2006, a partir de necessidades verificadas junto às escolas e aos jovens participantes, bem como pelo interesse de desenvolvimento de ensino e pesquisa, decidiu-se pela permanência do Projeto METUIA em uma daquelas escolas, justificada pelo fato de estar inserida numa região carente de bens sociais, por atender a alunos de grupos populares urbanos e por "implementar" as Diretrizes da Escola de Tempo Integral (São Paulo, 2006).

Ao se pensar a escola como um espaço de trocas democráticas, concorrendo para a busca da ampliação de direitos, propôs-se aos jovens inseridos no Ensino Médio protagonizarem ações sociais junto àquela comunidade escolar, desenvolvendo oficinas para adolescentes do Ensino Fundamental, na Escola de Tempo Integral. A equipe passou a contar com alunos de Ensino Médio dessa escola, na realização de Oficinas de

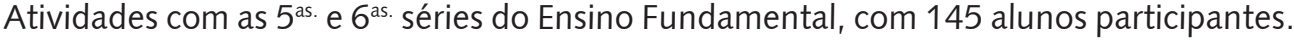

Em relação às estratégias para lidar com a demanda reconhecida, as intervenções foram orientadas para se fazerem, também, ouvir os professores, oferecendo-se espaços para a troca de ideias. Isso ocorria, apesar de algumas restrições, nas Horas de Trabalho Pedagógico Coletivo (HTPC), realizadas semanalmente com professores e a direção escolar.

Em 2007, a opção foi trabalhar com alunos inseridos nas $5^{\text {as. e }} 8^{\text {as. }}$ séries (cento e quarenta alunos). Esse fato originou-se de necessidades levantadas pelos próprios professores, que colocavam inúmeras dificuldades no desempenho de suas funções, em virtude de indisciplina, desrespeito e falta de motivação por parte dos alunos. Passamos a realizar, também, oficinas semanais abertas a todos os alunos, no pátio da escola, no horário do almoço, tendo como foco a temática da sexualidade.

No segundo semestre de 2007, as atividades foram reduzidas por conta da não-continuidade do financiamento, mas, a partir do apoio de outras parcerias firmadas e do empenho da própria equipe, algumas ações prioritárias puderam permanecer. Dessa maneira, as oficinas aconteciam com alunos do período noturno (Ensino Médio e Educação de Jovens e Adultos, atingindo diretamente 25 jovens e adultos), com enfoque na relação trabalho/emprego. No período diurno foi realizada uma oficina que capacitou seis adolescentes para o trabalho com recursos audiovisuais.

Em 2008 e 2009, mantivemos nossa inserção nessa escola com ações voltadas para alunos que apresentavam dificuldades cotidianas, especialmente no comportamento na escola. Muitos eram jovens que já estavam vinculados à nossa equipe, assim, as oficinas buscavam criar, dentro da escola, espaços que favorecessem a permanência desses jovens na educação formal. Acolhiam-se aproximadamente quarenta alunos de diferentes séries em duas oficinas semanais. Num primeiro momento, o espaço era para aqueles que apresentavam dificuldades na aquisição da leitura e da escrita; um segundo horário era destinado para os que apresentavam problemas em relação ao comportamento.

Em 2009, passamos novamente a intervir em sala de aula, fazendo uma parceria com a disciplina de Sociologia. Além disso, uma estratégia que permaneceu foi a do trabalho na hora do intervalo, com a criação de recursos interativos, com vistas a informar, esclarecer e tensionar os jovens acerca de temáticas de suas realidades.

As ações são semanais durante o período letivo, coordenadas por terapeutas ocupacionais, que contam com alunos de graduação e pós-graduação de diferentes níveis e cursos, com a presença de alunos da área de Terapia Ocupacional, Educação e Imagem e Som.

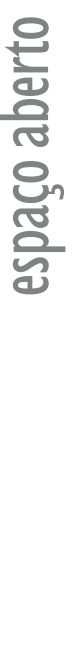


A Oficina de Atividades é uma ferramenta que tem propiciado um diálogo próximo com os jovens, permitindo ampliar as formas de se conceber a ação educativa inserida no interior da escola, objetivando seu fortalecimento e sua ressignificação para esses sujeitos.

É importante evidenciar um ponto fundamental com relação à escola pública: nela ainda encontramos o jovem pobre; disso decorre ser esse o espaço propício para o desenvolvimento de estratégias para a promoção e o fomento de projetos que possam garantir a esses jovens melhores condições de vida e experiências acerca da participação política e democrática. Para nós, a garantia dos direitos deve ser calcada na ampliação da esfera pública, apoiada no fortalecimento das ações e das políticas públicas com relação a setores sociais essenciais, como é o da educação (Lopes, Silva, 2007).

\section{As Oficinas de Atividades}

A proposição das Oficinas de Atividades tem base nos pressupostos teórico-metodológicos da Terapia Ocupacional Social, desenvolvidos por Barros, Ghirardi e Lopes $(2002,1999)$, e nas reflexões do educador Paulo Freire $(2005,1978)$.

A Terapia Ocupacional Social lança mão de atividades como recurso mediador do trabalho de aproximação, acompanhamento, apreensão das demandas e fortalecimento dos sujeitos, individuais e coletivos, para os quais direciona sua ação. A utilização da atividade possibilita o aprendizado e o reconhecimento de necessidades do sujeito e o desenvolvimento de sua capacidade para buscar soluções próprias e criativas, tornando a técnica dependente da interpretação e da apreensão da realidade, e não o inverso (Barros, Ghirardi, Lopes, 2002).

Por intermédio desse instrumento de trabalho, sobre o qual o terapeuta ocupacional deve ter amplo domínio, pode-se conhecer o universo imediato dos sujeitos e ser conhecido dentro dele, aumentando, de maneira significativa, a possibilidade de criação de vínculos e, a partir disso, gerar oportunidades para uma atuação profissional que contribua para a construção conjunta de planos e projetos de vida.

Um dos modos de concretização dessa metodologia tem sido nomeado de Oficinas de Atividades:

espaços constituídos por um agrupamento social nos quais são estabelecidas propostas relacionadas ao fazer, à ação humana, que promovem a aprendizagem compartilhada. Ressalta-se o caráter ativo do sujeito nesse processo assim como o caráter dinâmico dessas experiências relacionais: entre participantes, espaço, materiais, memória, sensações. (Silva, 2007a, p.213)

Dessa maneira, criam-se, potencialmente, espaços de experimentação e aprendizagem, concebendo cada participante como ser ativo no processo de construção de subjetividade, um ser da práxis, da ação e da reflexão.

A conjunção de fazeres, embebidos na leitura da função educativa de Paulo Freire, ganha um tom político, buscando:

uma educação que, por ser educação, haveria de ser corajosa, propondo ao povo a reflexão sobre si mesmo, sobre seu tempo, sobre suas responsabilidades, sobre seu papel no [...] clima cultural [...], que the propiciasse a reflexão sobre seu próprio poder de refletir e que tivesse sua instrumentalidade [...] no desenvolvimento desse poder, na explicitação de suas potencialidades, de que decorreria sua capacidade de opção. (Freire, 1978, p.59)

É a partir das (escolhas de quais) e nas (durante o processo) atividades que se objetiva a constituição de sujeitos históricos, sujeitos capazes de apreenderem sua realidade, de se conscientizarem e agirem sobre ela - transformando-a (Freire, 1978). 
${ }^{10}$ Ressalta-se que as atividades, além de serem criadas conjuntamente com os jovens na leitura de suas necessidades, desejos e vontades, contam com a participação de estudantes das áreas de

Terapia Ocupacional, Psicologia, Pedagogia e

Imagem e Som da

UFSCar. Esse coletivo potencializa a condição de pluralidade de oferta de atividades nas oficinas, uma vez que cada sujeito tem em si um repertório criativo a ser explorado e utilizado.

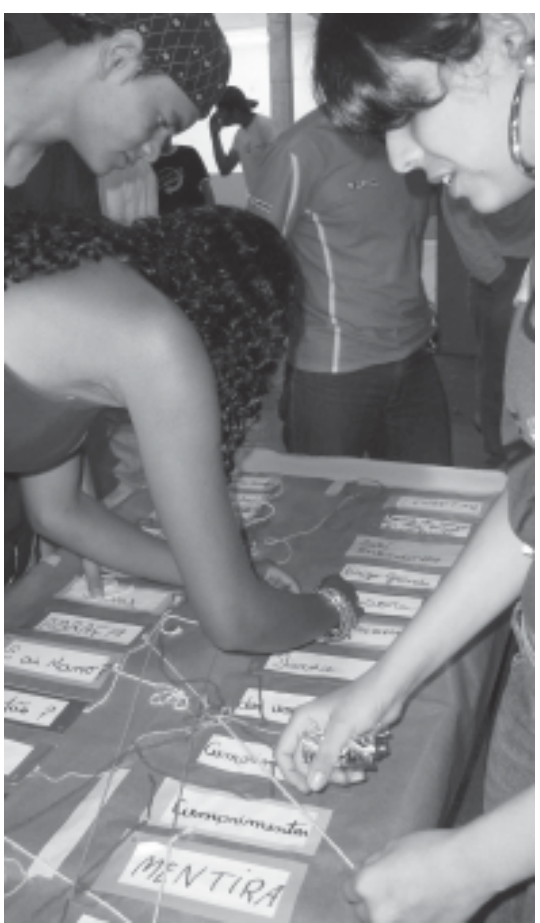

Figura 6. Construção de jogo interativo para trocas de informações
No entrelaçamento de pressupostos teórico-metodológicos e na perspectiva do trabalho coletivo ${ }^{10}$, intervimos por meio de diferentes recursos: jogos interativos, rodas de conversa, músicas, criação de paródias, leitura de imagens, fotografia, vídeo (elaboração e/ou fruição de documentários), construção de textos, esquetes, apresentações culturais, debates, dinâmicas de trocas de informações, entre outros. Esses recursos são comumente selecionados tendo como parâmetro a temática que se deseja focalizar: situações de violência, sexualidade, drogas, cidadania, política, trabalho, questões históricas sobre violações e conquistas de direitos, educação, projetos futuros.

O recurso da atividade permite um contato mais próximo com os jovens, a partir do qual se torna possível aprofundar a leitura das necessidades individuais e coletivas; também promove um maior contato e convivência entre os próprios participantes; proporciona a experimentação de um espaço prazeroso de sociabilidade e trocas que pode extrapolar o espaço físico da Oficina e transcender para o contexto escolar mais amplo. Outro impacto decorrente das atividades nas oficinas tem sido a ressignificação, por parte dos alunos, da importância da apreensão dos conteúdos curriculares da escola, pois as atividades, normalmente, preveem o domínio, em diferentes níveis, de "ferramentas" - como leitura, escrita, habilidades matemáticas, elementos históricos -, concretizando o que, convencionalmente, se denomina de trabalho com temas transversais.

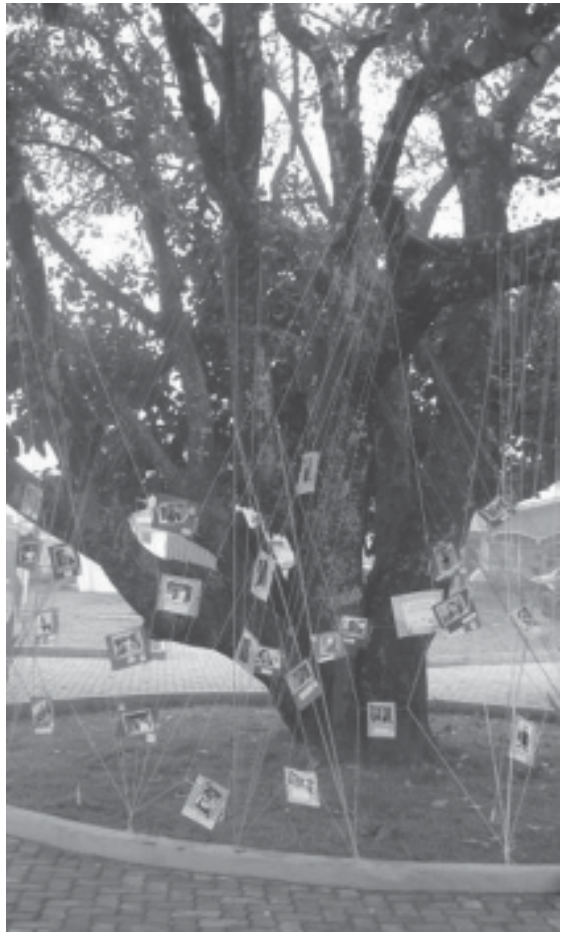

Figura 5. Leitura e fruição das imagens fotográficas das Oficinas

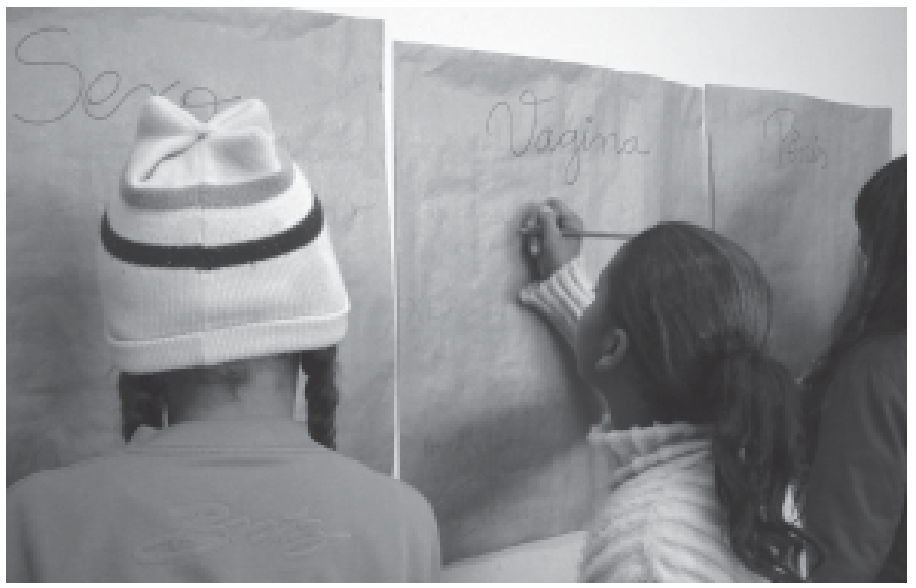

Figura 7. Trocas de informações acerca da sexualidade

OInterface comunicação Saúde educaçāo v.15, n.36, p.277-88, jan./mar. 2011 
A forma de condução das oficinas ganha centralidade quando se aposta no desenvolvimento da proposição da Educação de Tempo Integral, em especial, na sua última versão, amparado no projeto do governo do estado de São Paulo (São Paulo, 2006). Isso porque, segundo suas diretrizes gerais, as escolas devem oferecer oficinas curriculares, especialmente instituídas para a vivência de atividades de natureza prática, inovadora, integradas às temáticas, conhecimentos e saberes já interiorizados ou não pelos alunos.

Seriam oficinas articuladas aos planos de ensino dos diferentes professores, cujas prioridades estariam asseguradas na proposta de um processo que se destinasse à formação de pessoas aptas a exercerem sua plena cidadania. Essas oficinas deveriam buscar, em tempos complementares à educação formal: educar e cuidar da construção da imagem positiva do aluno; atender a diferentes necessidades de aprendizagem; promover o sentimento de pertinência e o desenvolvimento de atitudes de compromisso do aluno para com a escola e com a comunidade, instrumentalizando-o com as competências e habilidades necessárias ao desempenho do "protagonismo" juvenil e à participação social; promover a cultura da paz pelo desenvolvimento de atitudes de autorrespeito, respeito mútuo, solidariedade, justiça e diálogo (São Paulo, 2006). Abrangeriam uma ação política e social, com uma abordagem calcada na valorização da função social de uma escola de cunho humanista, qual seja: promover uma educação que se caracterize pelo exercício democrático tanto na construção de conhecimentos, quanto no desenvolvimento da individualidade e, também, como espaço privilegiado de construção de cultura e de sentidos (Lopes, Cuel, 2009).

Todavia, percebemos inúmeras dificuldades enfrentadas pelos atores escolares frente à implantação da Escola de Tempo Integral, primeiro por sua "implementação" ter acontecido de forma abrupta e verticalizada, seguida pela falta de subsídio físico e teórico-metodológico na forma da condução das oficinas curriculares (Castro, 2009; Lopes, Cuel, 2009).

Assim, a escola de tempo integral experimenta, muitas vezes, práticas incoerentes com as propostas e reivindica condições materiais e estruturais para que possa alcançar efetivamente os objetivos declarados.

Compreendemos que a metodologia de trabalho das Oficinas de Atividades, como vimos desenvolvendo, oferece parâmetros significativos para a discussão da temática da educação integral, inclusive com propostas concretas para as oficinas curriculares a serem realizadas nas escolas de tempo integral, que precisam extrapolar esse modelo e ocorrerem, igualmente, na escola formal de meio período, bem como em outros espaços que se imbuem da ação educativa como missão.

\section{Considerações finais}

As metodologias empregadas têm oportunizado a criação de vínculos importantes com os jovens que, desdobrando-se em acompanhamentos individuais, potencializam a ampliação das redes de suporte social; produzem espaços de convivência que possibilitam o respeito e a discussão, apresentando um novo referencial de como podem ser pautadas as relações dentro do espaço escolar. Isto porque, por um lado, promove-se a transferência de vínculos positivos para a escola, uma vez que eles, estimulados pelas vivências nas oficinas e pelos conhecimentos ali acessados e/ou construídos, ressignificam os processos e as experiências formais da escola; por outro lado, também temos nos deparado com situações conflitantes, sobretudo com parte do corpo docente, que encara as atividades das oficinas como ações concorrentes ao seu fazer "pedagógico", ao mesmo tempo em que os alunos passam a questionar, desde a perspectiva do direito, formas de tratamento que lhes são conferidas por alguns professores e funcionários.

A questão da escola e da educação como instâncias de exercício e reprodução das estruturas de poder parece tão clara quanto "inevitável", algo que perpassa a discussão das diferenças dentro da escola, característica que lhe é inerente, afinal, "a questão da diferença não é um componente externo, recentemente incorporado à reflexão pedagógica, mas um componente configurador [...] da prática pedagógica" (Candau, Koff, 2006, p.488). Deve, portanto, ser considerada e assumida para que se possibilite à escola cumprir seu papel de espaço democrático de confluência das diferenças, que a torne 
capaz de contribuir para o desenvolvimento de uma sociedade mais rica e complexa culturalmente, e com mais possibilidades de promover os ideais de igualdade, respeito e solidariedade.

A questão do exercício do poder dentro da escola deveria ser assumida e explicitada para que tivéssemos a possibilidade de transformá-la, no momento mesmo que refletimos sobre ela e sobre a possibilidade de subverter a lógica que rege essas relações, construindo novas arquiteturas, tecendo novas redes, que produzam tensões mais construtivas.

Enquanto a escola se mantiver apenas como reprodutora dos processos de exclusão que regem as relações em nossos contextos sociais, marcados por um modelo econômico e político que deles se alimenta, não realizará sua mais forte potencialidade: a de ser espaço de transformação social, capaz de permitir, a quem por ela passe (todos, por direito), trilhar caminhos para a conquista da autonomia.

É justamente no rompimento com a "tradicional" função reprodutora do ordenamento vigente e na ressignificação da função educativa da escola que se dá a possibilidade de transformação da escola e da sociedade.
A função educativa da escola [...] deve-se concretizar em dois eixos complementares de intervenção: - organizar o desenvolvimento radical da função compensatória das desigualdades de origem, mediante a atenção e o respeito pela diversidade; - provocar e facilitar a reconstrução dos conhecimentos, das disposições e das pautas de conduta que a criança assimila em sua vida paralela e anterior à escola. [...] preparar os alunos/as para pensar criticamente e agir democraticamente numa sociedade não democrática. (Gimeno Sacristán, Pérez Gómez, 1998, p.22)

Concordamos com esses autores quando pontuam que a escola obrigatória, que forma cidadãos, não pode se permitir o "fracasso escolar", pois este é o fracasso da cidadania e da sociedade.

A questão que ganha dimensão central nos estudos que correlacionam juventude e educação é o desafio que nos é apresentado por Manacorda, um dos principais educadores da contemporaneidade:
diante das exigências do mundo moderno, nós precisamos mirar o mais possível na preparação do aluno não somente para ser ele mesmo, mas também para entrar na sociedade, senão com a capacidade de ser um produtor de cultura em todos os campos, pelo menos para ter a capacidade de desfrutar, de saber gozar, de todas as contribuições da civilização, das artes, das técnicas, da literatura. A cultura deve ser direcionada para todos, facilitando as disposições intelectuais e ao mesmo tempo forçando todo mundo, com firme doçura a aprender e a participar de todos os prazeres humanos. (Manacorda apud Nosella, Lombardi, Saviani, 2007, p.23)

Talvez seja um tanto pretensioso considerarmos, com o acúmulo de experiências em que se baseia este relato, que avançamos no sentido desse processo anunciado por Manacorda; contudo, esta é uma de nossas utopias, entendida como direção do que temos tentado efetivar junto aos jovens frequentadores das Oficinas de Atividades.

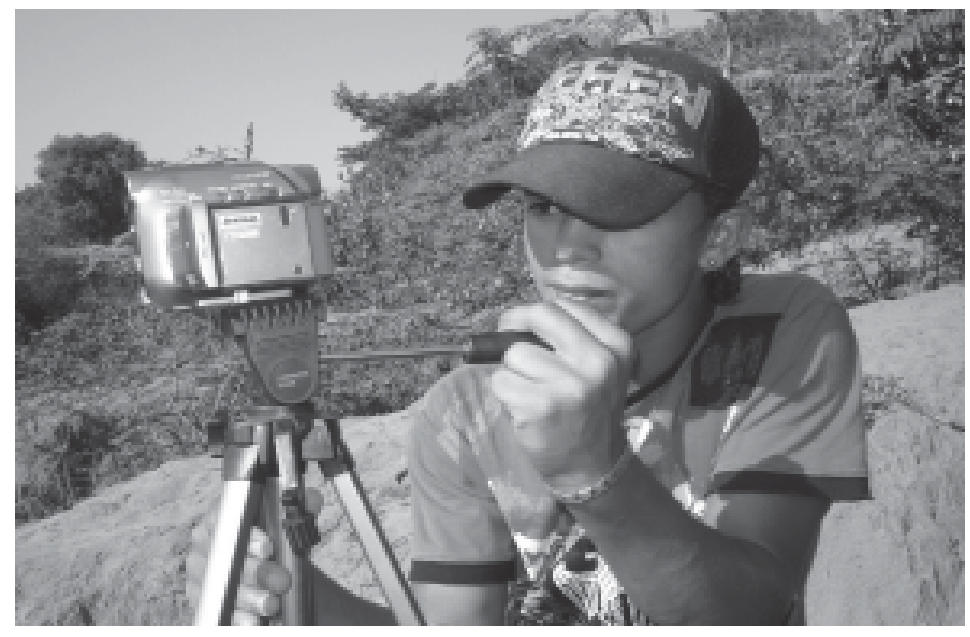

Figura 8. Elaboração de vídeos e documentários 


\section{Agradecimentos}

Aos alunos dos cursos de graduação da UFSCar que compuseram, e continuam compondo, as equipes de trabalho do METUIA/UFSCar. Em especial, aos jovens que têm participado conosco neste percurso de buscas e descobertas, por sua confiança.

\section{Colaboradores}

As autoras trabalharam juntas em todas as etapas de produção do manuscrito, com a coordenação da primeira.

\section{Referências}

BARROS, D.D.; GHIRARDI, M.I.G.; LOPES, R.E. Terapia ocupacional social. Rev. Ter. Ocup. Univ. São Paulo, v.13, n.2, p.95-103, 2002.

Terapia ocupacional e sociedade. Rev. Ter. Ocup. Univ. São Paulo, v.10, n.2-3, p.69-74, 1999.

BARROS, D.D.; LOPES, R.E.; GALHEIGO, S.M. Projeto Metuia: apresentação. In: SIMPÓSIO DE TERAPIA OCUPACIONAL SOCIAL, 1.; Congresso Brasileiro de Terapia Ocupacional, 10., 2007, Goiânia. Anais ... Goiânia: Associação dos Terapeutas Ocupacionais de Goiás e Associação Brasileira dos Terapeutas Ocupacionais, 2007. s/p. BOURDIEU, P. A distinção: crítica social do julgamento. São Paulo: Edusp, 2008. 1998.

A economia das trocas linguísticas: o que falar quer dizer. São Paulo: Edusp,

BOURDIEU, P.; SAINT-MARTIN, M. As categorias do juízo professoral. In: BOURDIEU, P. (Org.). 10.ed. Escritos da educação. Petrópolis: Vozes, 2008. p.185-216.

CANDAU, V.M.; KOFF, A.M.N.S. Conversas com... sobre a didática e a perspectiva multi/intercultural. Educ. Soc., v.27, n.95, p.471-93, 2006.

CARVALHO, A.; PINTO, M.V. Ser ou não ser... Quem são os adolescentes? In: CARVALHO, A.; SALLES, F.; GUIMARÃES, M. (Orgs.). Adolescência. Belo Horizonte: UFMG/PROEX, 2002. p.11-29.

CASTRO, A. A escola de tempo integral: a implantação do projeto em uma escola do interior paulista. 2009. Dissertação (Mestrado) - Programa de Pós-Graduação em Educação, Universidade Federal de São Carlos, São Carlos. 2009.

DEBORTOLI, J.A. Adolescência(s): identidade e formação humana. In: CARVALHO, A.; SALLES, F.; GUIMARÃES, M. (Orgs.). Adolescência. Belo Horizonte: UFMG/PROEX, 2002. p.31-47.

DIDI e MESTRINHO. É hoje. Samba Enredo G.R.E.S. União da Ilha do Governador. Rio de Janeiro: Top Tape Música Ltda, 1982. Disnponível em: <http://pt.wikipedia.org/ wiki/GRES_Uni\%C3\%A3o_da_Ilha_do_Governador\#cite_ref-14>. Acesso em: 10 jan. 2010 .

FERREIRA JR., A.; BITTAR, M. Proletarização e sindicalismo de professores na ditadura militar (1964-1985). São Paulo: Terras do Sonhar/Edições Pulsar, 2006.

FREIRE, P. Pedagogia do oprimido. 4.ed. Rio de Janeiro: Paz e Terra, 2005.

Pedagogia da autonomia. 12.ed. São Paulo: Paz e Terra, 1999.

Educação e mudança. Rio de Janeiro: Paz e Terra, 1979.

Educação como prática da liberdade. 8.ed. Rio de Janeiro: Paz e Terra, 1978. 
GIMENO SACRISTÁN, J.; PÉREZ GÓMEZ, A. As funções sociais da escola: da reprodução à reconstrução crítica do conhecimento e da experiência. In: (Orgs.). Compreender e transformar o ensino. 4.ed. Porto Alegre: ArtMed, 1998. p.13-25.

LOPES, R.E.; CUEL, B.T. (Re)Pensando o cotidiano na escola de tempo integral: a experiência de uma escola estadual na periferia da cidade de São Carlos (SP). São Carlos: Pró-Reitoria de Pesquisa da UFSCar/CNPq, 2009 (Relatório de pesquisa).

LOPES, R.E. et al. A formação de recursos humanos no território: a experiência do Núcleo UFSCar do Projeto METUIA no desenvolvimento de extensão, ensino e pesquisa. Anais do XI Encontro Nacional de Docentes de Terapia Ocupacional. São Paulo. Rev. Ter. Ocup. Univ. São Paulo, v.19, p.119-125, 2008a.

Juventude pobre, violência e cidadania. Saude Soc., v.17, n.3, p.63-76, 2008b.

LOPES, R.E.; SILVA, C.R. O campo da educação e demandas para a terapia ocupacional no Brasil. Rev. Ter. Ocup. Univ. São Paulo, v.18, n.3, p.158-64, 2007.

LOPES, R.E., SILVA, C.R., MALFITANO, A.P.S. Adolescência e juventude de grupos populares urbanos no Brasil e as políticas públicas: apontamentos históricos. HISTEDBR On-line, n.23, p.114-30, 2006.

MANACORDA, M. A. História da educação: da antiguidade aos nossos dias. São Paulo: Cortez, 1989.

MARCÍLIO, M.L. História da escola em São Paulo e no Brasil. São Paulo: Instituto Braudel/Imprensa Oficial, 2005.

NOSELLA, P.; LOMBARDO, J.C.; SAVIANI, D. (Orgs.). Mario Aligheiro Manacorda: aos educadores brasileiros. Campinas: Unicamp/HISTEDBR-FE/CNPq, 2007. p.1-26.

SÃO PAULO. Secretaria de Estado da Educação. Diretrizes da escola de tempo integral. São Paulo: Secretaria de Estado da Educação, 2006.

SILVA, C.R. Oficinas. In: PARK, M.B.; SIEIRO, R.F.; CARNICEL, A. (Orgs.). Palavras-chave da educação não formal. Holambra: Editora Setembro/Centro de Memória da Unicamp, 2007a. p.213-4.

SILVA, F.C. The matrix: a aventura da formação no mundo tecnologizado. Educ. Soc., v.28, n.101, p.1545-61, 2007b.

SORRENTINO, M. Desenvolvimento sustentável e participação: algumas reflexões em voz alta. In: LOUREIRO, C.F.B.; LAYRARGUES, P.P.; CASTRO, R.S. (Orgs.). Educação ambiental: repensando o espaço da cidadania. São Paulo: Cortez, 2002. v.1. p.15-21.

SPOSITO, M.P.; CORROCHANO, M.C. A face oculta da transferência de renda para jovens no Brasil. Tempo Soc., v.17, n.2, p.141-72, 2005. 
Discute-se uma experiência, na forma de Oficinas de Atividades, com jovens de uma escola pública. Trata-se de ações que decorrem de atividades de extensão universitária, caracterizadas por intervenções que buscam o exercício de metodologias participativas, fundamentadas na defesa de direitos que compõem a cidadania. Com o apoio dos pressupostos teórico-metodológicos da terapia ocupacional social e da educação para a liberdade defendida por Paulo Freire, as Oficinas de Atividades têm se constituído como uma tecnologia social de aproximação, (re)construção de projetos e ampliação de redes de suporte junto a jovens advindos de grupos populares urbanos em situação de vulnerabilidade social. O acúmulo dessas experiências tem nos oferecido subsídios para a discussão acerca da implantação desses dispositivos nos espaços da educação formal, com vistas à construção de propostas socieoeducativas fundadas em bases democráticas que carregam um movimento de tensionamento do ordenamento vigente, contribuindo para o enfrentamento de problemáticas sociais contemporâneas.

Palavras-chave: Juventude. Cidadania e direitos. Educação. Terapia Ocupacional. Tecnologias sociais.

\section{Activities workshops with public school youngsters: social technologies between education and occupational therapy}

This article discusses an experience with youngsters from a public school, developed as Activities Workshops. The experience included actions resulting from university extension activities, characterized by interventions that seek to exercise participative methodologies, based on the defense of the rights which compose citizenship. With the support of the theoretical and methodological presuppositions of social occupational therapy and education for freedom advocated by Paulo Freire, the Activities Workshops have been constituted as a social technology for approaching students, (re)building projects and enlarging support networks conducted with youngsters who come from urban popular groups and are in situations of social vulnerability. The sum of these experiences has provided us with subsides related to the discussion about the implementation of these devices into the schools' curriculum, in order to establish educational proposals founded on democratic bases that support a tensioning movement of the current situation, contributing to face contemporary social issues.

Keywords: Youth. Citizenship and rights. Education. Occupational Therapy. Social technologies.

Talleres de actividades con jóvenes de la escuela publica: tecnologías sociales entre la educación y terapia ocupacional

Se discute una experiencia en forma de talleres de actividades con jóvenes en una escuela pública. Se trata de acciones que resultan de actividades de extensión universitaria, caracterizadas por las intervenciones que buscan ejercer los métodos participativos, basados en la defensa de los derechos que componen la ciudadanía. Con el apoyo de los principios teóricos y metodológicos de la terapia ocupacional social y de la educación para la libertad defendida por Paulo Freire, los talleres de actividades han surgido como una tecnología social de aproximación, (re)construcción de proyectos y expansión de redes de apoyo a los jóvenes provenientes de grupos populares urbanos en situaciones de vulnerabilidad social. La acumulación de estas experiencias nos ha dado subsidios para la discusión sobre la implementación de estos dispositivos en la escuela que desea la construcción de propuestas sociales y educativas basadas en los fundamentos democráticos y con un movimiento de tensión de la situación actual.

Palabras clave: Juventud. Ciudadanía y derechos. Educación. Terapia Ocupacional. Tecnologías sociales. 